\title{
Active oxygen transport in tissue by interstitial flow
}

\author{
Zhu Liu, ${ }^{1,2, *}$ Chenyu Wen, ${ }^{2, *}$ Shi-Li Zhang ${ }^{2}$ \\ ${ }^{1}$ School of Physics and Astronomy, Yunnan University, Kunming 650504, Yunnan, PR \\ China \\ ${ }^{2}$ Division of Solid-State Electronics, Department of Electrical Engineering, Uppsala \\ University, SE-751 03 Uppsala, Sweden \\ *Corresponding author. Email: zhuliu@ynu.edu.cn, chenyu.wen@angstrom.uu.se
}

\section{Key points}

1. Interstitial flow plays a key role in active $\mathrm{O}_{2}$ transport in tissue due to its high Prandtl number $v / D \sim 10^{3}$;

2. $\mathrm{O}_{2}$ transport in tissue is balanced by both active convection and passive diffusion transport.

3. Interstitial flow in form of active convective transport can pump more than hundred times of $\mathrm{O}_{2}$ into tissue than those by passive diffusion transport due to the concentration gradient.

4. Active convection transport can be triggered by external pressure, which is crucial for damage tissue recovery.

\begin{abstract}
:
Oxygen $\left(\mathrm{O}_{2}\right)$ transport through diffusion from capillary to tissue has long been established by Krogh. However, the interstitial fluid in the interspace between tissue and capillary has a high Prandtl number around $10^{3}$ and hence its convective mass transport is more efficient than its diffusive transport. The interstitial flow drained by the initial lymphatics contributes to the convective transport of $\mathrm{O}_{2}$ through tissue, which can be modeled as aligned blood capillaries in parallel and the initial lymphatics. It is found that both the $\mathrm{O}_{2}$ concentration distribution and the total $\mathrm{O}_{2}$ flux are sensitive to the flow rate of interstitial fluid. The convection contribution has been evaluated based on the Peclet number, feature flow rate, and convection-diffusion boundary. At the same interstitial flow rate, convection delivers more $\mathrm{O}_{2}$ to type I muscle fibers with a higher concentration of myoglobin than to type IIX muscle fibers. Even with a small external
\end{abstract}


force, tissue with a higher specific hydraulic conductance (permeability) has a larger interstitial flow rate and a higher $\mathrm{O}_{2}$ transport rate than those in healthy tissue. Hence, the overall $\mathrm{O}_{2}$ transport from capillary to tissue includes two components, i.e., active convection transport by interstitial flow due to pressure gradient and passive diffusion transport due to concentration gradient. The active convective $\mathrm{O}_{2}$ transport is crucial for the recovery of damaged tissue where the contribution from passive diffusion transport is constrained by regulation of capillary opening. The convection facilitated $\mathrm{O}_{2}$ transport can be the basis for cell differentiation, morphogenesis, and therapeutic effects of massage and acupuncture.

Keywords: Active oxygen transport, interstitial flow, convective transport, diffusive transport, capillary, initial lymphatics 


\section{Introduction}

Human bodies rely on oxygen metabolism in mitochondria to produce the cellular energy adenosine triphosphate (ATP). During respiration, oxygen $\left(\mathrm{O}_{2}\right)$ is uptaken by the hemoglobin forming $\mathrm{Fe}-\mathrm{O}_{2}$ bond inside red blood cells. It is, then, circulated through blood streams to capillaries in peripherals. In capillaries, $\mathrm{O}_{2}$ dissociates from hemoglobin and dissolved in plasma, diffuses through the endothelium of capillaries. Finally, it reaches tissue and transports to mitochondria to participate in the ATP production. From the capillary to the tissue, $\mathrm{O}_{2}$ confronts the highest transport resistance due to its low solubility in the body fluid (Popel, 1989; Widmaier et al., 2007).

Krogh (Krogh, 1919b, a) introduced a model to describe the oxygen transport from capillary to tissue based on the passive diffusion of $\mathrm{O}_{2}$ inside the tissue. $\mathrm{He}$ also discovered the capillary regulation of opening and close at rest that governs this passive diffusion. Since then, the subsequent models have been developed in different scales from tissue to organs (Rakusan et al., 1984; Lagerlund \& Low, 1987; Popel, 1989), with various geometries (Hill, 1928) in multiple types of muscles and tumors (Wittenberg et al., 1975; Honig et al., 1984; Secomb et al., 2004). Similarly, all these models are constrained to pure diffusive transport, driven by the concentration gradient, without consideration of the $\mathrm{O}_{2}$ convective transport, i.e., the contribution of the body fluid movement.

The passive diffusive $\mathrm{O}_{2}$ transport only is difficult to recover the damaged tissue. As $\mathrm{O}_{2}$ consumptions can dramatically increase in sports as an example, opening more capillaries to enhance blood volume has been considered as the main strategy to produce more ATP to fulfill the $\mathrm{O}_{2}$ demands. However, if the tissue is in fatigue with lactic acid byproducts or even injured, the $\mathrm{O}_{2}$ transport is inhibited by a reduced mitochondria metabolism. At such conditions, $\mathrm{O}_{2}$ reimbursement is a perquisite to recovering the damaged tissue back to health. Diseases, such as covid-19, which directly attack the respiration system and reduce the total $\mathrm{O}_{2}$ uptake in body, could leave a damaged tissue with pulmonary fibrosis in patients. The passive $\mathrm{O}_{2}$ diffusion transport only depends on the demand, i.e., the concentration gradient. However, the damaged tissue with impeached mitochondria metabolism cannot retrigger the $\mathrm{O}_{2}$ demand 
automatically. It means that, unless with certain assistance of active $\mathrm{O}_{2}$ transport, the damaged tissue cannot recover only by passive $\mathrm{O}_{2}$ diffusion.

The $\mathrm{O}_{2}$ transport from the capillary to the tissue is conveyed by the interstitial fluid, a dynamic movement flow for maintaining nutrition metabolism of body. In the interstitial fluid, the Prandtl number, $v / D$, of $\mathrm{O}_{2}$ is $\sim 10^{3}$, where, $v=10^{-6} \mathrm{~m}^{2} / \mathrm{s}$ is the viscosity of interstitial fluid and $D_{O 2}=1.6 \times 10^{-9} \mathrm{~m}^{2} / \mathrm{s}$ is the $\mathrm{O}_{2}$ diffusion coefficient. The large Prandtl number indicates that convective transport in the interstitial fluid is more effective than diffusive transport even low flow rates (Levich, 1962). Hence, the convective transport of interstitial fluid should be included in the $\mathrm{O}_{2}$ transport from the capillary to tissue.

The interstitial flow is a one-way movement from the capillary to the initial lymphatics. The interstitial fluid includes blood plasma, water, proteins, and electrolytes leaked from capillary (Guyton \& Hall, 2006). For a healthy tissue, 10-20\% of the excess interstitial fluid is drained by the initial lymphatics and the rest is reabsorbed by the venous capillaries. Hence, the lymph formation and the lymph flow rate regulate the flow rate of interstitial fluid (Breslin et al., 2018; Goswami et al., 2020). Lymphatic vessels locate inside the connective tissues and distribute across the entire muscle tissues correlated with arcading arterioles and veins (Skalak et al., 1984). In muscle tissues, the initial lymphatics has a luminal size about $10-100 \mu \mathrm{m}$ with an average distance of several hundred micrometers (Skalak et al., 1984; Schmid-Schonbein, 1990). However, the initial lymphatics does not have smooth muscles, and thus cannot contract spontaneously. Their openness is controlled by contraction of surrounding muscle fibers and arterial pulsations (McMaster \& Parsons, 1938; Skalak et al., 1984; Mazzoni et al., 1990). The typical interstitial flow rate, $\boldsymbol{u}$, is in the range of $0.1-2 \mu \mathrm{m} / \mathrm{s}$ (Swartz \& Fleury, 2007). During exercises, the lymph flow can increase by more than 10-30 folds (Havas et al., 1997; Guyton \& Hall, 2006). At the lymphedema condition due to disease or injury, the lymph flow is almost ceased, rendering the interstitial fluid and tissue swollen (Schmid-Schonbein, 1990; Swartz, 2001). Therefore, the interstitial flow maintains nutrition and body fluid metabolism. The entire process is balanced by the venous pressure, interstitium composition, interstitial pressure, and pressure inside lymphatic vessels (Granger, 1979; Aukland \& Reed, 1993; Swartz \& Fleury, 2007). 
The interstitial flow through tissue has been found to facilitate protein transport, drug deliveries, and therapeutics (Reddy et al., 2006a; Reddy et al., 2006b; Dukhin \& Labib, 2013). The convection is an active process prone to local external force offered by, such as, massage and body stretch (Olszewski \& Engeset, 1980; Guyton \& Hall, 2006). The interstitium can tune its porosity and permeability responding to tissue deformation and compression (Zhang et al., 2000; McGuire et al., 2006). Furthermore, manipulating large molecules through interstitium to tumor sites by enhancing its convective transport has been investigated as an effective way in cancer therapies (Heldin et al., 2004; Dreher et al., 2006). In addition, the convective transport of interstitial flow is important in nutrition delivery for cartilage and bone modeling (Piekarski \& Munro, 1977; Evans $\&$ Quinn, 2006). For soft tissue, the interstitial flow is very sensitive to local pressure and permeability of the tissue. The morphogenesis, differentiation, and regeneration of cells closely correlate to the interstitial flow (Fleury et al., 2006; Goldman et al., 2007; Rutkowski \& Swartz, 2007). Moreover, the interstitial flow has been correlated to the meridian channel theory (Li et al., 2008; Zhang et al., 2015; Li et al., 2020). Therefore, the convective transport is a crucial mass transport process in interstitial fluid.

In this work, the convection-diffusion transport process has been thoroughly solved in a one-dimensional (1D) framework by introducing a critical flow rate, $u_{\mathrm{dc}}$, and a spatial convection-diffusion boundary, $x_{0}$. The muscle tissue with different muscle fibers is represented by varying the myoglobin concentration. Darcy's law is introduced to state the relationship between tissue permeability and local pressure gradient. A comprehensive picture of $\mathrm{O}_{2}$ transport in tissue is presented by considering the convective component of the interstitial flow and the diffusive component driven by concentration gradient.

\section{Convective and diffusive transport of $\mathrm{O}_{2}$ inside tissue}

The $\mathrm{O}_{2}$ flux from the capillary to the tissue, $J_{\text {total }}$, includes two parts: molecular diffusion, $J_{\mathrm{D}}$, and convection of interstitial flow, $J_{\text {conv }}$.

$$
J_{\text {total }}=J_{D}+J_{\text {conv }}
$$

The $\mathrm{O}_{2}$ diffusion across a surface of unit area per unit time is described by Fick's first law: 


$$
J_{D}=-D_{O 2} \nabla C_{\mathrm{O} 2}
$$

where, $\mathrm{C}_{\mathrm{O} 2}$ is $\mathrm{O}_{2}$ concentration gauged by its partial pressure $\left(\mathrm{O}_{2}\right.$ tension $) P_{\mathrm{O} 2}$. $C_{\mathrm{O} 2}=\alpha P_{\mathrm{O} 2}, \alpha$ is the solubility coefficient of the body fluid $\left(1.23 \mathrm{~mol} / \mathrm{m}^{3}\right.$ torr $)$. The convective transport by the interstitial fluid flow of rate $\boldsymbol{u}[\mathrm{m} / \mathrm{s}]$ is:

$$
J_{\text {conv }}=C_{\mathrm{O}_{2}} \boldsymbol{u}
$$

Assuming a homogeneous consumption of $\mathrm{O}_{2}$ inside the tissue by mitochondria with a rate of $M_{0}\left[\mathrm{~mol} \cdot \mathrm{m}^{-3} \mathrm{~s}^{-1}\right]$, the $\mathrm{O}_{2}$ transport in a volume tissue is equal to the $\mathrm{O}_{2}$ flux through the tissue boundary and the consumption within the tissue volume, which can be described by Fick's second law:

$$
\frac{d C_{O_{2}}}{d t}=D_{O_{2}} \nabla^{2} C_{O_{2}}-\boldsymbol{u} \nabla C_{0}-M_{0}
$$

For impressible fluid, $\nabla \cdot \boldsymbol{u}=0$. At steady state, $\mathrm{d} C_{\mathrm{O} 2} / \mathrm{d} t=0$, and the above equation can be simplified as:

$$
D_{O_{2}} \nabla^{2} C_{O_{2}}-\boldsymbol{u} \nabla C_{O_{2}}-M_{0}=0
$$

It is difficult to solve equation (5) in two-dimensional (2D) or three-dimensional (3D) domains. However, it can be solved analytically in a $1 \mathrm{D}$ domain where the capillary is assumed to lie in parallel to the initial lymphatics with distance $b$ and the following boundary conditions: at $x=0$ (location of the capillary), $C_{\mathrm{O} 2}=C_{0}=\alpha P_{0}$; at $x=b$ (location of the initial lymphatics), $\nabla C=0$, as shown in Fig. 1. Although the analytical solution is approximate and not so accurate as the $3 \mathrm{D}$ result, the $1 \mathrm{D}$ model suffices to provide critical insights into the physics of convection and diffusion of $\mathrm{O}_{2}$, a vital element in human body. Note that the interstitial flow is a one-way movement from the capillary to the initial lymphatics. The close form of solution of equation (5) is:

$$
C(x)=C_{0}-\frac{M_{0}}{\boldsymbol{u}} x-\frac{D M_{0}}{\boldsymbol{u}^{2}} \exp \left(-\frac{\boldsymbol{u}}{D} b\right)\left[1-\exp \left(\frac{\boldsymbol{u}}{D} x\right)\right]
$$

Substituting equation (6) into equation (1-3), $J_{\mathrm{D}}$ and $J_{\text {conv }}$ can be obtained as follows:

$$
\begin{gathered}
J_{D}=-D_{O_{2}} \nabla C_{O_{2}}=\frac{M_{0} D}{\boldsymbol{u}}\left\{1-\exp \left[-\frac{\boldsymbol{u}}{D}(b-x)\right]\right\} \\
J_{\text {conv }}=C_{O_{2}} \boldsymbol{u}=C_{0} \boldsymbol{u}-M_{0} x+\frac{D M_{0}}{\boldsymbol{u}} \exp \left(-\frac{\boldsymbol{u}}{D} b\right)\left[\exp \left(\frac{\boldsymbol{u}}{D} x\right)-1\right] \\
J_{\text {total }}=J_{\text {conv }}+J_{D}\left(O_{2}\right)=C_{0} \boldsymbol{u}+\frac{D M_{0}}{\mathbf{u}}\left[1-\exp \left(-\frac{\boldsymbol{u}}{D} b\right)\right]-M_{0} x
\end{gathered}
$$

Details in mathematical derivations can be found in Appendix. The $\mathrm{O}_{2}$ concentration distribution along $x$ can be resolved, so does the convective and diffusive transport 
fluxes. Since the actual distance between the capillary and the initial lymphatics is around several hundred micrometers, a typical value of $b=1 \mathrm{~mm}$ is selected in our calculation. In addition, a 1D numerical simulation is implemented by using COMSOL Multiphysics. The related parameters used in the calculation and simulation are listed in Table 1.

\section{Results:}

The distribution of $\mathrm{O}_{2}$ tension across the tissue is shown in Fig. 2(A), without considering the fluid movement, i.e., convention. The penetration length of $\mathrm{O}_{2}$ is determined by $L_{\mathrm{p}}=\left(2 D C_{0} / M_{0}\right)^{1 / 2}$ (Hill, 1928) (see Appendix). If $b$ is less than, i.e., $b<$ $L_{\mathrm{p}}$, the $\mathrm{O}_{2}$ flux can reach the initial lymphatics by diffusion; while, if $b \geq L_{\mathrm{p}}, \mathrm{O}_{2}$ is extinguished by mitochondria consumption before reaching the initial lymphatics. In this situation, part of the tissue is under the condition of hypoxia and fatigue. Therefore, the critical initial $\mathrm{O}_{2}$ tension with $b=L_{\mathrm{p}}$ is $P_{\mathrm{O} 2}\left(L_{\mathrm{p}}\right)=b^{2} M_{0} /\left(2 D \alpha C_{0}\right)$. As the interstitial fluid flow increases, the $\mathrm{O}_{2}$ concentration gradient decreases but the $\mathrm{O}_{2}$ concentration at the lymphatic capillary $(x=b)$ increases, as shown in Fig. 2(B). Hence, $\boldsymbol{u}$ changes the diffusive transport of $\mathrm{O}_{2}$ and accelerates the $\mathrm{O}_{2}$ flux through the tissue.

The normalized $\mathrm{O}_{2}$ flux at $x=0$ is used to characterize the total $\mathrm{O}_{2}$ input into the entire tissue region (from 0 to $b$ ) as shown in Fig. 3(A). At very small flow rate, i.e., $u<$ $0.1 \mu \mathrm{m} / \mathrm{s}$, the total $\mathrm{O}_{2}$ flux into the tissue remains almost unchanged. However, it grows exponentially when the flow rate increases further. The ratio of the $\mathrm{O}_{2}$ convective flux to the total flux is displayed in Fig. 3(B). Three regions of $\mathrm{O}_{2}$ transport can be discerned: i) convection wherein the $\mathrm{O}_{2}$ transport is predominated by the interstitial fluid movement and the total $\mathrm{O}_{2}$ flux is linearly dependent on the flow rate; ii) convection-diffusion in which both the interstitial fluid movement and the concentration gradient have large effects on the $\mathrm{O}_{2}$ transport and the total $\mathrm{O}_{2}$ flux into the tissue increases dramatically with the flow rate; and iii) diffusion where the flow rate of interstitial fluid is too small to affect the concentration gradient of $\mathrm{O}_{2}$ and the $\mathrm{O}_{2}$ transport is dominated by diffusion.

Normally, the convection and diffusion contributions can be evaluated by the Peclet number, $\boldsymbol{P} e=\boldsymbol{u} b / D$. However, even with a small $\boldsymbol{P} e$ number, the flow rate of the 
interstitial fluid can influence the concentration gradient due to different $\mathrm{O}_{2}$ tension conditions as shown in Fig. 3(B). Hence, the total $\mathrm{O}_{2}$ consumption in the tissue $\left(b M_{0}\right)$ and $L_{\mathrm{p}}$. are included in the following discussion.

\section{i) Convection regime $(\mathrm{Pe}>1)$}

In the convection regime, $\boldsymbol{u} b>>D, \exp (-\boldsymbol{u} b / D) \sim 0, J_{\mathrm{D}}=D M_{0} / \boldsymbol{u}$, and $J_{\mathrm{D}} \sim 0$. Thus, the $\mathrm{O}_{2}$ concentration is constant across the tissue. Then, the $\mathrm{O}_{2}$ transport solely relies on the interstitial fluid movement expressed as:

$$
J_{\text {conv }}=C_{O_{2}} \boldsymbol{u}=C_{0} \boldsymbol{u}-M_{0} x
$$

At $x=0$, the $\mathrm{O}_{2}$ flux into the tissue is $J_{\text {conv }}=J_{\text {total }}=C_{0} \boldsymbol{u}$, with $J_{\text {conv }} / J_{\text {total }}=1$. The total $\mathrm{O}_{2}$ flux into the tissue depends on the initial $\mathrm{O}_{2}$ tension and $u$.

ii) Convection-diffusion regime $(\boldsymbol{P} e \sim 1)$

At $x=0$, equation (5) becomes:

$$
\begin{gathered}
J_{D}=-D_{O_{2}} \nabla C_{O_{2}}=\frac{M_{0} D}{\boldsymbol{u}}\left[1-\exp \left(-\frac{\boldsymbol{u}}{D} b\right)\right] \\
J_{\text {conv }}=C_{0} \boldsymbol{u} \\
J_{\text {total }}=C_{0} \boldsymbol{u}+\frac{D M_{0}}{\boldsymbol{u}}\left[1-\exp \left(-\frac{\boldsymbol{u}}{D} b\right)\right]
\end{gathered}
$$

In this region, $J_{\mathrm{D}} / J_{\text {conv }} \sim \boldsymbol{u}^{-2}$. The concentration gradient is very sensitive to $\boldsymbol{u}$. The total input flux into the muscle increases with $\boldsymbol{u}$, while the gradient of the concentration decreases as a result of a higher convective contribution. In the convection-diffusion regime, both diffusive and convective fluxes are correlated to the body fluid flow rate. Hence, the total flux is sensitive to the body flow rate.

iii) Diffusion/convection-diffusion regime $(P e<1)$

If $\boldsymbol{P} e<1$, the transport is dominated by the diffusive transport. However, if the flow rate is large enough to modify the concentration gradient, convection can also contribute significantly to the $\mathrm{O}_{2}$ transport inside the tissue.

In this region, $\boldsymbol{u}<D / b, 1-\exp (-\boldsymbol{u} b / D)=\boldsymbol{u} b / D$. Then, equation (5) becomes:

$$
\begin{gathered}
J_{\text {total }}=J_{\text {conv }}+J_{D}\left(O_{2}\right)=C_{0} \boldsymbol{u}+M_{0}(b-x) \\
J_{D}=M_{0}(b-x) \\
J_{\text {conv }}=C_{0} \boldsymbol{u}
\end{gathered}
$$

At $x=0, \boldsymbol{u}<u_{\mathrm{dc}}, J_{\mathrm{D}} / J_{\text {conv }}$ can be expressed as a sigmoid function:

$$
\frac{J_{\text {conv }}}{J_{\text {total }}}=\frac{\boldsymbol{u} / u_{d c}}{1+\boldsymbol{u} / u_{d c}}
$$




$$
u_{d c}=\frac{M_{0} b}{C_{0}}
$$

where, $u_{\mathrm{dc}}$ is the critical flow rate at which the $\mathrm{O}_{2}$ delivery by the interstitial flow into the tissue is equal to that by the concentration-gradient induced diffusion. For $M_{0} b=$ $10^{-7} \mathrm{~mol} / \mathrm{m}^{2} \mathrm{~s}, C_{0}=\alpha P_{0}(50$ torr $)=6.2 \times 10^{-2} \mathrm{~mol} / \mathrm{m}^{3}$ and $u_{\mathrm{dc}}=1.6 \mu \mathrm{m} / \mathrm{s}$.

Hence, for low flow rate, the diffusive flux of $\mathrm{O}_{2}$ is a function of the distance inside the tissue, $x$. The boundary between the convection dominated region and the diffusion dominated region is expressed by $x_{0}$ :

$$
x_{0}=b\left(1-\frac{\boldsymbol{u}}{\boldsymbol{u}_{d c}}\right)
$$

At $x=x_{0}, J_{\mathrm{D}}=J_{\text {conv. }}$. The amount of $\mathrm{O}_{2}$ molecules delivered by the interstitial flow is the same as the amount by diffusion. For $x<x_{0}, J_{\mathrm{D}}>J_{\text {conv. }}$ The mass transport of $\mathrm{O}_{2}$ to the site is prevalent by diffusion. For $x>x_{0}, J_{\mathrm{D}}<J_{\text {conv }}$. The $\mathrm{O}_{2}$ transport to the site mainly relies on convection.

However, for $b>L_{\mathrm{p}}$, the diffusive flux is determined by the $\mathrm{O}_{2}$ consumption rate, $L_{\mathrm{p}} M_{0}$ :

$$
u_{d c}=\frac{M_{0} L_{p}}{C_{0}}=\sqrt{\frac{2 D M_{0}}{C_{0}}}
$$

then

$$
x_{0}=L_{p}\left(1-\frac{\boldsymbol{u}}{u_{d c}}\right)
$$

It can be found in Fig. 4(A) that $u_{\mathrm{dc}}$ drops as the $\mathrm{O}_{2}$ tension of capillary increases. Furthermore, $x_{0}$ moves from the initial lymphatics to the capillary as $\boldsymbol{u}$ rises from 0 to $u_{\mathrm{dc}}$, as shown in Fig. 4(B). In the hypoxia condition, i.e., $b>L_{\mathrm{p}}$, the $\mathrm{O}_{2}$ gradient cannot provide enough $\mathrm{O}_{2}$ reaching the tissue in the deep. Hence, the hypoxia region is sensitive to the fluid movement in which the $\mathrm{O}_{2}$ delivery relies mainly on the interstitial fluid. Therefore, it is difficult to recover the $\mathrm{O}_{2}$ metabolism in tissue only unless there is an external force to drive the interstitial flow.

\section{Muscle types}

Inside muscle fibers, myoglobin can store $\mathrm{O}_{2}$ and facilitate $\mathrm{O}_{2}$ transport at the same time (Popel, 1989). Muscle type I fiber has the largest concentration of mitochondria and myoglobin, while muscle type IIX fiber has the lowest concentration. The 
concentration of the $\mathrm{O}_{2}$ loaded myoglobin $\left(C_{\mathrm{Mb}-\mathrm{O} 2}\right)$ can be expressed as a function of $C_{\mathrm{O} 2}$ according the Hill equation (Hill, 1910):

$$
C_{M b-O_{2}}=\frac{C_{M b}^{T} K C_{O_{2}}}{1+K C_{O_{2}}}
$$

where, $C_{\mathrm{Mb}}{ }^{\mathrm{T}}$ is the total concentration of uniformly distributed myoglobin $(0-1 \mathrm{mM})$ and $K$ is the reaction equilibrium constant. Assuming the muscle tissue with uniform myoglobin distribution allows to evaluate the effects of myoglobin concentration on the $\mathrm{O}_{2}$ transport. Substituting equation (22) into (1), the diffusive flux of $\mathrm{O}_{2}$ becomes:

$$
\begin{gathered}
J_{D}=-D_{O_{2}} \nabla C_{O_{2}}-D_{M b-O_{2}} \nabla C_{M b-O_{2}} \\
J_{c o n v}=C \boldsymbol{u}, \quad C=C_{O_{2}}+C_{M b-O_{2}}
\end{gathered}
$$

where, $D_{\mathrm{Mb}}\left(1 \times 10^{-6} \mathrm{~cm}^{2} / \mathrm{s}\right)$ is the diffusion coefficient of myoglobin (Covell \& Jacquez, 1987 ) by assuming $D_{\mathrm{Mb}}=D_{\mathrm{Mb}-\mathrm{O} 2}$.

It is clear that $u_{\mathrm{dc}}$ is linearly dependent on the myoglobin concentration, as shown in Fig. 5(A). $u_{\mathrm{dc}}$ reduces to $0.16 \mu \mathrm{m} / \mathrm{s}$ as the concentration of the myoglobin increases to 1 $\mathrm{mM}$. It means that at the same interstitial flow and $\mathrm{O}_{2}$ tension, the convective transport contributes more $\mathrm{O}_{2}$ flux to the slow-twitch muscle tissue with type I muscle fiber than that to the fast-twitch muscle tissue with type IIX fiber. The convective flux ratio of the total $\mathrm{O}_{2}$ flux with and without myoglobin can be found in Fig. 5(B). The convection-diffusion region shifts to smaller $u_{\mathrm{dc}}$ as the myoglobin concentration increases.

\section{Tissue permeability}

Darcy's law is usually used to describe porous media. Hence, the flow is directly proportional to pressure gradient and $\boldsymbol{u}$ through the tissue can be expressed as follows:

$$
\boldsymbol{u}=\frac{\kappa}{\mu} \nabla \boldsymbol{P}=\frac{\kappa}{\mu} \frac{\boldsymbol{P}}{b}
$$

where, $\kappa$ is the tissue permeability or specific hydraulic conductivity of tissue, in unit of $\left[\mathrm{m}^{2}\right], \mu$ is the dynamic viscosity of $u$ and $\mu=1 \times 10^{-3}$ [Pa s] for water, and $\boldsymbol{P}$ is the pressure exerted at $x=0$. The value of $\kappa$ depends on the tissue type, the hydrate of the interspace, pressure, and interestitium composites such as proteins, collagen fibers, etc. (Guyton et al., 1966; Levick, 1987) 
The linear relationship between the pressure gradient and tissue permeability $\kappa$ is shown in Fig. 6, without considering the pressure dependence of the tissue permeability. At the same pressure, the flow is much easier to go through the tissue with lower $\kappa$. Typical tissue permeability $\kappa$ values are in the range of $10^{-11}$ to $10^{-15} \mathrm{~m}^{2}$ (Swartz \& Fleury, 2007). But tissue permeability can increase by more than $10^{5}$ times above the atmospheric pressure (Guyton et al., 1966), for example, in acute edema conditions. Therefore, the interstitial flow in tissue with acute edema is sensitive to the external force, which suggests that even a small force can achieve high flow rate and regulate $\mathrm{O}_{2}$ transport inside the tissue.

\section{Discussion}

The $\mathrm{O}_{2}$ transport inside the muscle tissue is here modeled by including the convection transport of the interstitial flow with the diffusion transport. It has now been established that the interstitial flow plays a key role in the $\mathrm{O}_{2}$ transport in tissue through convective transport. The $\mathrm{O}_{2}$ transport due to convection can be evaluated by examining $\mathbf{P e}, u_{\mathrm{dc}}$, and $x_{0}$. At the large flow rate, $\mathbf{u}>>u_{\mathrm{dc}}(\mathbf{P e}>>1)$, the convection by the interstitial flow can pump hundreds times $\mathrm{O}_{2}$ flux into the tissue than those by the passive diffusion transport. As for small flow rate, $\boldsymbol{u}<u_{\mathrm{dc}}(\mathrm{Pe}<1)$, contribution of convection transport can be expressed by a sigmoid function: $J_{\text {conv }} / J_{\text {total }}=\left(\boldsymbol{u} / u_{\mathrm{dc}}\right) /\left(1+\boldsymbol{u} / u_{\mathrm{dc}}\right)$. In addition, $x_{0}$ defines the spatial contribution of the convective $\mathrm{O}_{2}$ transport in tissue for $\boldsymbol{u}<u_{\mathrm{dc}}$. As $\boldsymbol{u}$ increases from 0 to $u_{\mathrm{dc}}, x_{0}$ moves from the initial lymphatics distance towards the capillary. This movement reflects that diffusion is more effective in transport near the capillary for $\boldsymbol{u}<u_{\mathrm{dc}}$. In contrast, the convective transport is crucial for the $\mathrm{O}_{2}$ delivery to any point far from the capillary. Moreover, if there is a fatigue region due to the low $\mathrm{O}_{2}$ tension, the initial lymphatics is much easy to reach the hypoxia condition because the diffusion penetration length is insufficient to delivery $\mathrm{O}_{2}$ to the initial lymphatics. Thus, the convective transport with a faster flow is required to recover the ATP production near the initial lymphatics due to its higher $u_{d c}$.

For muscle tissues, interstitial flow has large accelerating effects on the $\mathrm{O}_{2}$ transport in the slow twitch muscle with type I fiber than on the fast twitch muscle due to its higher myoglobin concentration. The tissue permeability and the magnitude of pressure 
gradient in tissue are crucial to driving the interstitial flow. For the tissue with a higher tissue permeability such as in the edema condition, a small external force can change the $\mathrm{O}_{2}$ transport through the tissue.

In this model, the interstitial flow is through the entire tissue, a uniform porous media, including muscle fibers. Here, the cell permeability of water molecules is converted into the apparent tissue permeability. The effect of myoglobin concentration on $\mathrm{O}_{2}$ transport in muscle tissues is highlighted by ignoring the fact that myoglobin molecules are only located inside the muscle fiber not in the interstitial interspace. This difference could affect the net calculated $\mathrm{O}_{2}$ input flux in tissue but has nothing to do with its effects on the $\mathrm{O}_{2}$ transport.

\section{Interstitial flow with capillary regulation and $\mathrm{O}_{2}$ influx into tissue}

The correlation between the interstitial flow and $\mathrm{O}_{2}$ influx to tissue is schematically shown in Fig. 7. At the balanced metabolism, the interstitial flow is leaked from the capillary and drained by the initial lymphatics. Therefore, the interstitial flow provides a positive and negative feedback for the blood stream in the capillary and the $\mathrm{O}_{2}$ influx into the tissue, respectively. If interstitial flow $\boldsymbol{u}$ increases, both the lymph formation and the $\mathrm{O}_{2}$ convective transport are enhanced. The speedy $\mathrm{O}_{2}$ transport from the capillary also accelerates the $\mathrm{O}_{2}$ dissociation from hemoglobin $\left(\mathrm{Hb}-\mathrm{O}_{2}\right)$ in red blood cells. Consequently, the faster interstitial flow further increases the hydraulic and osmosis pressure gradient between the inside (2) and outside (3) of the capillary shown in Fig. 7, and causes more plasma leak from the capillary. In sequence, more plasma leaking from the capillary reduces the local hydraulic pressure inside the capillary (2)and builds up a large hydraulic pressure gradient ( $\Delta \mathrm{P}$ ) from upstream (1) inside the capillary, and thus drives more blood stream to the local capillary. Hence, the $\mathrm{O}_{2}$ mitochondria metabolism can benefit from the fast convective $\mathrm{O}_{2}$ transport and the blood volume increases due to the positive feedback of interstitial flow $\boldsymbol{u}$.

If interstitial flow $\boldsymbol{u}$ becomes low, a negative feedback leads to a sluggish blood stream and an inactive $\mathrm{O}_{2}$ mitochondria metabolism. Moreover, the static interstitial fluid may accumulate in the tissue and causes further edema. 


\section{Model of active and passive $\mathrm{O}_{2}$ transport inside tissue}

For tissue metabolism, both the convective transport by interstitial flow and the diffusive transport by concentration gradient play a key role in the $\mathrm{O}_{2}$ transport in tissue. The diffusive $\mathrm{O}_{2}$ transport is governed by the capillary regulation and the $\mathrm{O}_{2}$ tension inside the capillary, which corresponds to the microcirculation and system metabolism of the body. The convective transport is governed by the interstitial flow and can be tuned by a local pressure gradient and drainage of the initial lymphatic. To restore the $\mathrm{O}_{2}$ mitochondria metabolism of damaged tissues, it is convenient by stimulating an active interstitial flow to facilitate the $\mathrm{O}_{2}$ transport by a local pressure gradient. Hence, the convective contribution by the interstitial flow resembles an active $\mathrm{O}_{2}$ transport that can be triggered by exerting an external force, while the diffusive contribution by the concentration gradient is a passive $\mathrm{O}_{2}$ transport governed by the capillary regulation.

Hence, $\mathrm{O}_{2}$ transport from capillary to mitochondria in tissue follows active and passive routes as summarized in Fig. 8. The passive diffusive $\mathrm{O}_{2}$ transport in tissue is driven by the concentration gradient, and the corresponding model has been established by Krogh about 100 years ago. The active convective $\mathrm{O}_{2}$ transport in tissue is determined by the interstitial flow, which can be caused by pressure gradient.

During a balanced metabolism, the diffusive transport can provide sufficient $\mathrm{O}_{2}$ flux for mitochondria near the capillary. However, this passive supply is insufficient for the distant mitochondria. The convective transport by the interstitial flow can delivery $\mathrm{O}_{2}$ effectively to the distant mitochondria in tissue, since the moment transfer is more rapid than molecular mass transfer in form of diffusion due to a high Prandtl number of $v / D \sim$ $10^{3}$ in the interstitial fluid. For damaged tissues, capillaries are in regulation to respond to the reduced $\mathrm{O}_{2}$ mitochondria metabolism. Thus, a concentration gradient cannot sustain enough $\mathrm{O}_{2}$ to the far end of the tissue as what the interstitial flow can. Therefore, the convective transport by the interstitial flow is crucial for recovery of damaged mitochondria metabolism, which can be activated by external forces.

\section{The significance of active $\mathrm{O}_{2}$ transport in tissue}

For microcirculation metabolism, the interstitial flow through tissue is driven by the drainage of the initial lymphatics. This interstitial flow drainage may be easily blocked 
by damaged tissues and constrained by the dysfunctional local muscle contraction, render that the passive $\mathrm{O}_{2}$ diffusion transport is the only route to maintain the tissue metabolism in damaged tissue. Therefore, driving the interstitial flow through tissue could enable $\mathrm{O}_{2}$ redistribution and reimburse $\mathrm{O}_{2}$ deficiency of tissue.

Hence, the $\mathrm{O}_{2}$ transport through convection is very import for tissues in fatigue and during excise. In fatigue tissues where lactic acids accumulate locally or tissues damaged by injury inducing the regulation of capillaries, the diffusive transport cannot provide enough $\mathrm{O}_{2}$ for the tissues to recover with closed capillaries and reduced $\mathrm{O}_{2}$ demand of mitochondria. Thus, an external force is needed to drive the interstitial flow, and facilitate the $\mathrm{O}_{2}$ transport through tissue to recover the tissue metabolism. During exercises, muscle tissues demand $\mathrm{O}_{2}$ rapidly, and $\mathrm{O}_{2}$ stored in the myoglobin can only last for few seconds during long time aerobic exercise such running and swimming. It has been observed that the lymphatic flow can increase by more than 10 folds from the level in the resting condition. Concurrently, the blood volume increases with more capillaries being opened to deliver more $\mathrm{O}_{2}$. Based on our convective-diffusion model of the $\mathrm{O}_{2}$ transport inside the tissue, the physiology mechanism behind the significant enhancement of interstitial flow is to trigger the active convection $\mathrm{O}_{2}$ transport in tissue to sustain the sudden $\mathrm{O}_{2}$ demand of tissue during exercises.

The interstitial flow provides an additional route for $\mathrm{O}_{2}$ transport through tissue, accompanying with diffusion. It can be used to explain the phenomena that interstitial flow can influence cell morphogenesis and differentiation even with small flow rate. Since the interstitial flow facilitates not only the nutrition delivery but also $\mathrm{O}_{2}$ transport, it provides more ATP for cell morphogenesis and differentiation along the interstitial flow and orientated by ATP production and $\mathrm{O}_{2}$ metabolism of mitochondria.

\section{Perspective of active and passive $\mathrm{O}_{2}$ transport in tissue}

ATP produced by mitochondria for $\mathrm{O}_{2}$ metabolism is the main energy source for tissue. Our convection-diffusion model of $\mathrm{O}_{2}$ transport shows that the lymphatic drainage of the interstitial flow is a crucial driving force for the $\mathrm{O}_{2}$ transport through tissues besides its function of nutrition delivery. Typically, $\boldsymbol{u}$ is around $0.1-2 \mu \mathrm{m} / \mathrm{s}$. This range is close to $u_{\mathrm{dc}}$ at which both diffusion and convection play the similar role for the 
$\mathrm{O}_{2}$ transport. Hence, the $\mathrm{O}_{2}$ transport through convection and diffusion is sensitive to $\boldsymbol{u}$ in this flow range i.e, small fluctuation of the interstitial flow can impact the $\mathrm{O}_{2}$ transport in tissue.

A local pressure gradient can stimulate the active $\mathrm{O}_{2}$ transport through tissue and promote microcirculation. Traditional therapies, such as massage and cupping, provide local force to the tissue so as to enhance the local interstitial fluid, enhance the $\mathrm{O}_{2}$ transport, and rebuild the local $\mathrm{O}_{2}$ metabolism. Physical exercises, such as yoga, Taichi, and other stretching movements, would stimulate the contraction of lymphatic vessels with smooth muscles and directly facilitate the lymphatic flow (Guyton \& Hall, 2006). All this results in a fast drainage of the interstitial fluid and a high-flux rate $\mathrm{O}_{2}$ delivery. For covid-19 patients, as an example, it could be possible for a therapy route to recover the $\mathrm{O}_{2}$ deficiency of local tissues if a suitable way can be found to trigger the active $\mathrm{O}_{2}$ transport in pulmonary tissues, in addition to enhancing the $\mathrm{O}_{2}$ intake by using a ventilator.

\section{Conclusion}

The interstitial flow provides an alternative active route for the $\mathrm{O}_{2}$ transport from capillary to tissue along with its counterpart of diffusion. It also provides a perspective to understand the morphogenesis and differentiation of cells. Moreover, the comprehensive picture of the $\mathrm{O}_{2}$ transport suggests that the traditional therapies, such as massage and stretch, could facilitate the $\mathrm{O}_{2}$ transport from capillary to tissue to promote the tissue recovery from hypoxia. Based on this mechanism, acupuncture with magnetic needles can drive the interstitial flow to enhance the $\mathrm{O}_{2}$ flux and rebuild the $\mathrm{O}_{2}$ metabolism of tissue, which can be found in our follow-up paper.

\section{Appendix}

\section{1. $\mathrm{O}_{2}$ diffusive transport}

The capillary is parallel the lymphatic capillary with the distance $b$. The tissue has a constant $\mathrm{O}_{2}$ consumption rate $M_{0}$ by the mitochondria. From Fick's first law, if no convection contribution, the $\mathrm{O}_{2}$ flux per area per second is:

$$
J_{D}=-\mathrm{D}_{\mathrm{O}_{2}} \nabla \mathrm{C}_{\mathrm{O}_{2}}
$$


The flux into the tissue per second can be expressed by Fick's second law:

$$
\frac{d \mathrm{C}_{O_{2}}}{d t}=\mathrm{D}_{O_{2}} \nabla^{2} \mathrm{C}_{O_{2}}-M_{0}
$$

Equation (A1) and (A2) can be solved at the steady state $d C_{\mathrm{O} 2} / d t=0$ with the boundary condition: $C_{\mathrm{O} 2}=C_{0}=\alpha P_{0}$, at $x=0$, and $\nabla C=0$, at $x=b$.

$$
C_{O 2}=C_{0}+\frac{M_{0}}{2 D} x(x-2 b)
$$

The total $\mathrm{O}_{2}$ flux $J_{\text {total }}$ into the tissue from the capillary is corresponding to the $\mathrm{O}_{2}$ flux at $x=0$. Substituting equation (A3) into equation (A1), we can obtain:

$$
J_{D}=M_{0}(b-x)
$$

At $x=0, J_{\mathrm{D}}=M_{0} b$.

\section{Including $\mathrm{O}_{2}$ convective transport}

If the total flux is determined by the gradient of concentration and the body fluid flow $\boldsymbol{u}$, the total $\mathrm{O}_{2}$ flux becomes

$$
\begin{gathered}
J_{\text {total }}=J_{D}+J_{\text {conv }}=-\mathrm{D}_{O_{2}} \nabla \mathrm{C}_{O_{2}}+\mathrm{C}_{O_{2}} \mathbf{u} \\
\frac{d \mathrm{C}_{O_{2}}}{d t}=\mathrm{D}_{O_{2}} \nabla^{2} \mathrm{C}_{O_{2}}-\mathbf{u} \nabla C_{0}-M_{0}
\end{gathered}
$$

The liquid is impressible and $\nabla \cdot \boldsymbol{u}=0$. At the steady state, with the boundary conditions are: $C_{\mathrm{O} 2}=C_{0}=\alpha P_{0}$, at $x=0$, and $\nabla C=0, x=b$. The equation can be solved at steady state. Let

$$
y=\frac{d C}{d x}+\frac{M_{0}}{\mathbf{u}}
$$

Equation (A6) becomes:

$$
\begin{gathered}
0=\mathrm{D}_{O_{2}} \nabla y-\mathbf{u} y \\
\mathrm{y}=\operatorname{Aexp}\left(\frac{\mathbf{u}}{D} x\right)
\end{gathered}
$$

where, $A$ is a constant. With the boundary condition $\nabla C=0$ at $x=b$, we can obtain

$$
\begin{gathered}
\mathrm{A}=\frac{M_{0}}{\mathbf{u}} \exp \left(-\frac{\mathbf{u}}{D} b\right) \\
\mathrm{y}=\frac{M_{0}}{\mathbf{u}} \exp \left(-\frac{\mathbf{u}}{D}(b-x)\right)
\end{gathered}
$$

Substituting equation (A11) into equation (A7),

$$
\begin{gathered}
\frac{M_{0}}{\mathbf{u}} \exp \left(-\frac{\mathbf{u}}{D}(b-x)\right)=\frac{d C}{d x}+\frac{M_{0}}{\mathbf{u}} \\
C=\frac{M_{0}}{\mathbf{u}}\left(-x+\frac{D}{\mathbf{u}} \exp \left(-\frac{\mathbf{u}}{D}(b-x)\right)\right)+B
\end{gathered}
$$


The constant $B$ can be determined by the boundary condition $C_{\mathrm{O} 2}=C_{0}$ at $x=0$.

$$
B=C_{0}-\frac{D M_{0}}{\mathbf{u}^{2}} \exp \left(-\frac{\mathbf{u}}{D} b\right)
$$

Thus, equation (A13) becomes:

$$
\mathrm{C}=\mathrm{C}_{0}-\frac{M_{0}}{\mathbf{u}} x-\frac{D M_{0}}{\mathbf{u}^{2}} \exp \left(-\frac{\mathbf{u}}{D} b\right)\left(1-\exp \left(\frac{\mathbf{u}}{D} x\right)\right)
$$

The diffusion flux component is:

$$
J_{D}=-\mathrm{D}_{O_{2}} \nabla \mathrm{C}_{O_{2}}=\frac{M_{0} D}{\mathbf{u}}\left(1-\exp \left(-\frac{\mathbf{u}}{D}(b-x)\right)\right)
$$

The convection flux component is:

$$
J_{c o n v}=\mathrm{C}_{O_{2}} \mathbf{u}=\mathrm{C}_{0} \mathbf{u}-M_{0} x+\frac{D M_{0}}{\mathbf{u}} \exp \left(-\frac{\mathbf{u}}{D} b\right)\left(\exp \left(\frac{\mathbf{u}}{D} x\right)-1\right)
$$

The total flux is:

$$
\mathrm{J}=J_{c o n v}+\mathrm{J}_{D}\left(O_{2}\right)=\mathrm{C}_{0} \mathbf{u}+\frac{D M_{0}}{\mathbf{u}}\left(1-\exp \left(-\frac{\mathbf{u}}{D} b\right)\right)-M_{0} x
$$

If $\boldsymbol{u} b<\mathrm{D}$, following the first order expansion,

$$
\begin{gathered}
1-\exp \left(-\frac{\mathbf{u} b}{D}\right)=1-\left(1-\frac{\mathbf{u} b}{D}\right)=\frac{\mathbf{u} b}{D} \\
\mathrm{C}=\mathrm{C}_{0}-\frac{M_{0}}{\mathbf{u}} x-\frac{D M_{0}}{\mathbf{u}^{2}} \exp \left(-\frac{\mathbf{u}}{D} b\right)\left(1-\exp \left(\frac{\mathbf{u}}{D} x\right)\right) \\
\mathrm{C}=\mathrm{C}_{0}-\frac{M_{0}}{\mathbf{u}} x-\frac{D M_{0}}{\mathbf{u}^{2}}\left(1-\frac{\mathbf{u} b}{D}\right)\left(1-\exp \left(\frac{\mathbf{u}}{D} x\right)\right) \\
\mathrm{C}=\mathrm{C}_{0}-\frac{M_{0}}{\mathbf{u}} x-\frac{D M_{0}}{\mathbf{u}^{2}}\left(1-\exp \left(\frac{\mathbf{u}}{D} x\right)\right)+\frac{b M_{0}}{\mathbf{u}}\left(1-\exp \left(\frac{\mathbf{u}}{D} x\right)\right) \\
\left(\exp \left(-\frac{\mathbf{u}}{D} b\right)-\exp \left(-\frac{\mathbf{u}}{D}(b-x)\right)\right)=\left(1-\frac{\mathbf{u} b}{D}\right)-\left(1-\frac{\mathbf{u}}{D}(b-x)\right)=-\frac{\mathbf{u} x}{D}(A 2) \\
\mathrm{J}=J_{\text {conv }}+\mathrm{J}_{D}\left(O_{2}\right)=\mathrm{C}_{0} \mathbf{u}+\frac{D M_{0}}{\mathbf{u}}\left(\frac{\mathbf{u}}{D} b\right)-M_{0} x=\mathrm{C}_{0} \mathbf{u}+M_{0}(b-x) \\
\mathrm{J}_{D}=M_{0}(b-x)
\end{gathered}
$$

At $x=0$,

$$
\begin{gathered}
J_{\text {total }}=\mathrm{C}_{0} \mathbf{u}+\frac{D M_{0}}{\mathbf{u}}\left(1-\exp \left(-\frac{\mathbf{u}}{D} b\right)\right) \\
J_{\text {conv }}=\mathrm{C}_{0} \mathbf{u} \\
\mathrm{J}_{D}=\frac{M_{0} D}{\mathbf{u}}\left(1-\exp \left(-\frac{\mathbf{u}}{D} b\right)\right)
\end{gathered}
$$

For $\mathbf{u} b<\mathrm{D}, J_{\mathrm{D}}=M_{0} b$. 


$$
\frac{J_{D}}{J_{c o n v}}=\frac{M_{0} b}{\mathrm{C}_{0} \mathbf{u}}
$$

\section{Authors contributions:}

Z.L. conceived the idea. Z.L. discussed with C.W. on the physiology aspects of the idea and with S.-L.Z. on the physics aspects. Z.L. worked on model design, mathematical derivations, data analysis, and drafted the manuscript. C.W. built the COMSOL model. All authors contributed to the manuscript revision.

Funding: Financial support from Chinese oversea program CSC foundation 201907035003 and Faculty fund of Uppsala University. 


\section{References:}

Aukland K \& Reed RK. (1993). Interstitial-lymphatic mechanisms in the control of extracellular fluid volume. Physiological reviews 73, 1-78.

Breslin JW, Yang Y, Scallan JP, Sweat RS, Adderley SP \& Murfee WL. (2018). Lymphatic Vessel Network Structure and Physiology. Compr Physiol 9, 207-299.

Covell DG \& Jacquez JA. (1987). Does myoglobin contribute significantly to diffusion of oxygen in red skeletal muscle? American Journal of Physiology-Regulatory, Integrative and Comparative Physiology 252, R341-R347.

Dreher MR, Liu W, Michelich CR, Dewhirst MW, Yuan F \& Chilkoti A. (2006). Tumor vascular permeability, accumulation, and penetration of macromolecular drug carriers. Journal of the National Cancer Institute 98, 335-344.

Dukhin SS \& Labib ME. (2013). Convective diffusion of nanoparticles from the epithelial barrier toward regional lymph nodes. Advances in colloid and interface science 199, 23-43.

Evans RC \& Quinn TM. (2006). Solute convection in dynamically compressed cartilage. Journal of biomechanics 39, 1048-1055.

Fleury ME, Boardman KC \& Swartz MA. (2006). Autologous morphogen gradients by subtle interstitial flow and matrix interactions. Biophysical journal 91, 113-121.

Goldman J, Conley KA, Raehl A, Bondy DM, Pytowski B, Swartz MA, Rutkowski JM, Jaroch DB \& Ongstad EL. (2007). Regulation of lymphatic capillary regeneration by interstitial flow in skin. American Journal of Physiology-Heart and Circulatory Physiology 292, H2176-H2183.

Goswami AK, Khaja MS, Downing T, Kokabi N, Saad WE \& Majdalany BS. (2020). Lymphatic Anatomy and Physiology. Semin Intervent Radiol 37, 227-236.

Granger HJ. (1979). Role of the interstitial matrix and lymphatic pump in regulation of transcapillary fluid balance. Microvascular Research 18, 209-216.

Guyton AC \& Hall JE. (2006). The Microcirculation and the Lymphatic System: Capillary Fluid Exchange, Interstitial Fluid, and Lymph Flow. In Textbook of medical physiology, pp. 184-193. Elsvier Saunders.

Guyton AC, Scheel K \& Murphree D. (1966). Interstitial fluid pressure: III. Its effect on resistance to tissue fluid mobility. Circulation Research 19, 412-419. 
Havas E, Parviainen T, Vuorela J, Toivanen J, Nikula T \& Vihko V. (1997). Lymph flow dynamics in exercising human skeletal muscle as detected by scintography. The Journal of Physiology 504, 233-239.

Heldin C-H, Rubin K, Pietras K \& Östman A. (2004). High interstitial fluid pressure-an obstacle in cancer therapy. Nature Reviews Cancer 4, 806-813.

Hill AV. (1910). The possible effects of the aggregation of the molecules of haemoglobin on its dissociation curves. j physiol 40, 4-7.

Hill AV. (1928). The diffusion of oxygen and lactic acid through tissues. Proceedings of the Royal Society of London Series B, Containing Papers of a Biological Character 104, 39-96.

Honig C, Gayeski T, Federspiel W, Clark A \& Clark P. (1984). Muscle O 2 gradients from hemoglobin to cytochrome: new concepts, new complexities. In Oxygen Transport to Tissue-V, pp. 23-38. Springer.

Krogh A. (1919a). The number and distribution of capillaries in muscles with calculations of the oxygen pressure head necessary for supplying the tissue. J Physiol 52, 409-415.

Krogh A. (1919b). The supply of oxygen to the tissues and the regulation of the capillary circulation. $J$ Physiol 52, 457-474.

Lagerlund TD \& Low PA. (1987). A mathematical simulation of oxygen delivery in rat peripheral nerve. Microvascular research 34, 211-222.

Levich VG. (1962). Convective diffusion in liquid. In Physicochemical Hydrodynamics, pp. 53. Prentice-Hall Inc, Englewood Cliffs, N.J.

Levick J. (1987). Flow through interstitium and other fibrous matrices. Quarterly Journal of Experimental Physiology: Translation and Integration 72, 409-437.

Li H-Y, Yang J-F, Chen M, Xu L, Wang W-C, Wang F, Tong J-B \& Wang C-Y. (2008). Visualized regional hypodermic migration channels of interstitial fluid in human beings: are these ancient meridians? The Journal of Alternative and Complementary Medicine 14, 621-628.

Li H, Yin Y, Yang C, Chen M, Wang F, Ma C, Li H, Kong Y, Ji F \& Hu J. (2020). Active interfacial dynamic transport of fluid in a network of fibrous connective tissues throughout the whole body. Cell Proliferation 53, e12760. 
Mazzoni MC, Skalak TC \& Schmid-Schonbein GW. (1990). Effects of skeletal muscle fiber deformation on lymphatic volumes. American Journal of Physiology-Heart and Circulatory Physiology 259, H1860-H1868.

McGuire S, Zaharoff D \& Yuan F. (2006). Nonlinear dependence of hydraulic conductivity on tissue deformation during intratumoral infusion. Annals of biomedical engineering 34, 1173-1181.

McMaster PD \& Parsons RJ. (1938). The effect of the pulse on the spread of substances through tissues. The Journal of experimental medicine 68, 377-400.

Olszewski WL \& Engeset A. (1980). Intrinsic contractility of prenodal lymph vessels and lymph flow in human leg. American Journal of Physiology-Heart and Circulatory Physiology 239, H775-H783.

Piekarski K \& Munro M. (1977). Transport mechanism operating between blood supply and osteocytes in long bones. Nature 269, 80-82.

Popel AS. (1989). Theory of oxygen transport to tissue. Critical reviews in biomedical engineering 17, 257.

Rakusan K, Hoofd L \& Turek Z. (1984). The effect of cell size and capillary spacing on myocardial oxygen supply. In Oxygen Transport to Tissue-VI, pp. 463-475. Springer.

Reddy ST, Berk DA, Jain RK \& Swartz MA. (2006a). A sensitive in vivo model for quantifying interstitial convective transport of injected macromolecules and nanoparticles. Journal of applied physiology 101, 1162-1169.

Reddy ST, Rehor A, Schmoekel HG, Hubbell JA \& Swartz MA. (2006b). In vivo targeting of dendritic cells in lymph nodes with poly (propylene sulfide) nanoparticles. Journal of Controlled Release 112, 26-34.

Rutkowski JM \& Swartz MA. (2007). A driving force for change: interstitial flow as a morphoregulator. Trends in Cell Biology 17, 44-50.

Schmid-Schonbein GW. (1990). Microlymphatics and lymph flow. Physiological reviews 70, 987-1028.

Secomb TW, Hsu R \& Dewhirst MW. (2004). Synergistic effects of hyperoxic gas breathing and reduced oxygen consumption on tumor oxygenation: a theoretical model. International journal of radiation oncology, biology, physics $59,572-578$.

Skalak T, Schmid-Schönbein G \& Zweifach B. (1984). New morphological evidence for a mechanism of lymph formation in skeletal muscle. Microvascular research 28, 95-112. 
Swartz MA. (2001). The physiology of the lymphatic system. Advanced drug delivery reviews 50, 3-20.

Swartz MA \& Fleury ME. (2007). Interstitial flow and its effects in soft tissues. Annu Rev Biomed Eng 9, 229-256.

Widmaier EP, Raff H \& Strang KT. (2007). Vander's Human Physiology: the mechanisms of body function. McGraw-Hill High Education.

Wittenberg BA, Wittenberg JB \& Caldwell PR. (1975). Role of myoglobin in the oxygen supply to red skeletal muscle. J Biol Chem 250, 9038-9043.

Zhang W-B, Wang G-J \& Fuxe K. (2015). Classic and modern meridian studies: A review of low hydraulic resistance channels along meridians and their relevance for therapeutic effects in Traditional Chinese Medicine. Evidence-based Complementary and Alternative Medicine 2015.

Zhang X-Y, Luck J, Dewhirst MW \& Yuan F. (2000). Interstitial hydraulic conductivity in a fibrosarcoma. American Journal of Physiology-Heart and Circulatory Physiology 279, H2726-H2734. 
Table 1. Parameters used in the COMSOL simulation (Covell \& Jacquez, 1987)

\begin{tabular}{|c|c|c|c|}
\hline$k_{1}$ & $24 \times 10^{3} \mathrm{~m}^{3} \mathrm{~mol}^{-1} \mathrm{~s}^{-1}$ & $K=k_{1} / k_{2}$ & $3.69 \times 10^{2} \mathrm{~m}^{3} \mathrm{~mol}^{-1}$ \\
\hline$k_{2}$ & $65 \mathrm{~s}^{-1}$ & $\alpha$ & $1.23 \times 10^{-3} \mathrm{~mol} \mathrm{~m}^{-3}$ torr $^{-1}$ \\
\hline$C_{\mathrm{Mb}}{ }^{\mathrm{T}}$ & $0-1 \mathrm{mM}$ & $P_{0}$ & $50 \mathrm{torr}^{-1}$ \\
\hline$D_{\mathrm{O} 2}$ & $1.6 \times 10^{-9} \mathrm{~m}^{2} \mathrm{~s}^{-1}$ & $b$ & $1 \mathrm{~mm}$ \\
\hline$D_{\mathrm{Mb}}$ & $10^{-10} \mathrm{~m}^{2} \mathrm{~s}^{-1}$ & $M_{0}$ & $10^{-4} \mathrm{~mol} \mathrm{~m}^{-3} \mathrm{~s}^{-1}$ \\
\hline
\end{tabular}

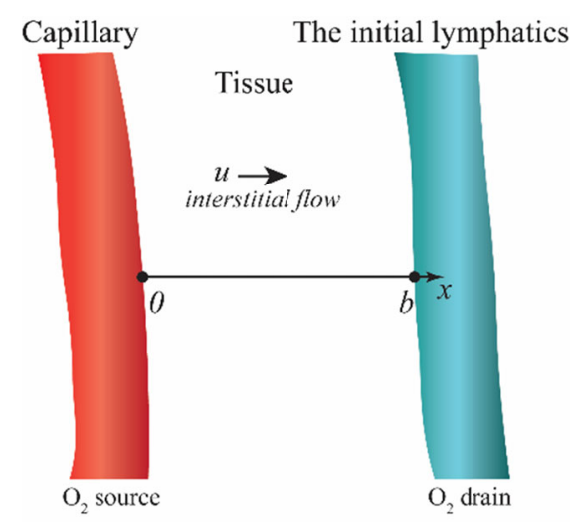

Figure 1. Illustration of a $1 \mathrm{D}$ model for the $\mathrm{O}_{2}$ transport from the capillary $(x=0)$ to the initial lymphatics $(x=b)$
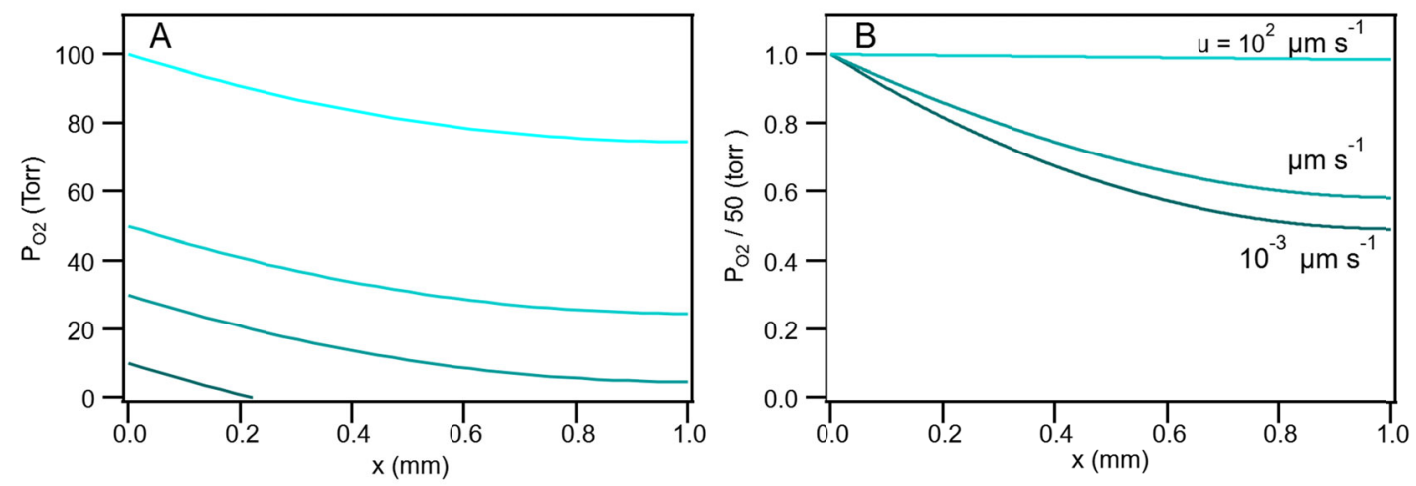

Figure 2. Concentration profile at different (A) $\mathrm{O}_{2}$ tension of capillary and (B) fluid flow rate $\left(10^{-9}, 10^{-6}\right.$ and $\left.10^{-4} \mathrm{~m} / \mathrm{s}\right)$ at $P_{\mathrm{O}_{2}}=50$ torr. 

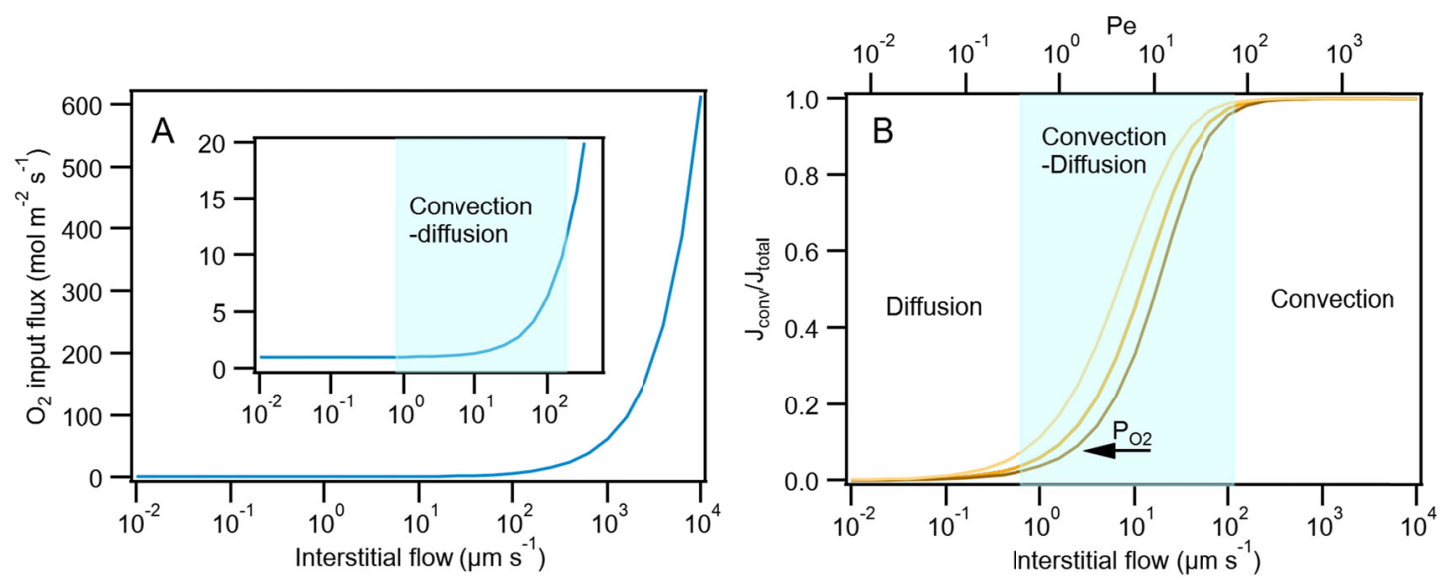

Figure 3. At $x=0$, (A) the ratio plot of $J_{\text {tconv }} / J_{\text {total }}(\boldsymbol{u}=0)$ as a function of the fluid flow with the inset for an enlarged image; (B) the ratio of $J_{\text {conv }} / J_{\text {total }}$ as a function of the interstitial flow, at $P_{\mathrm{O} 2}=30,50$, and 100 Torr from right to left.
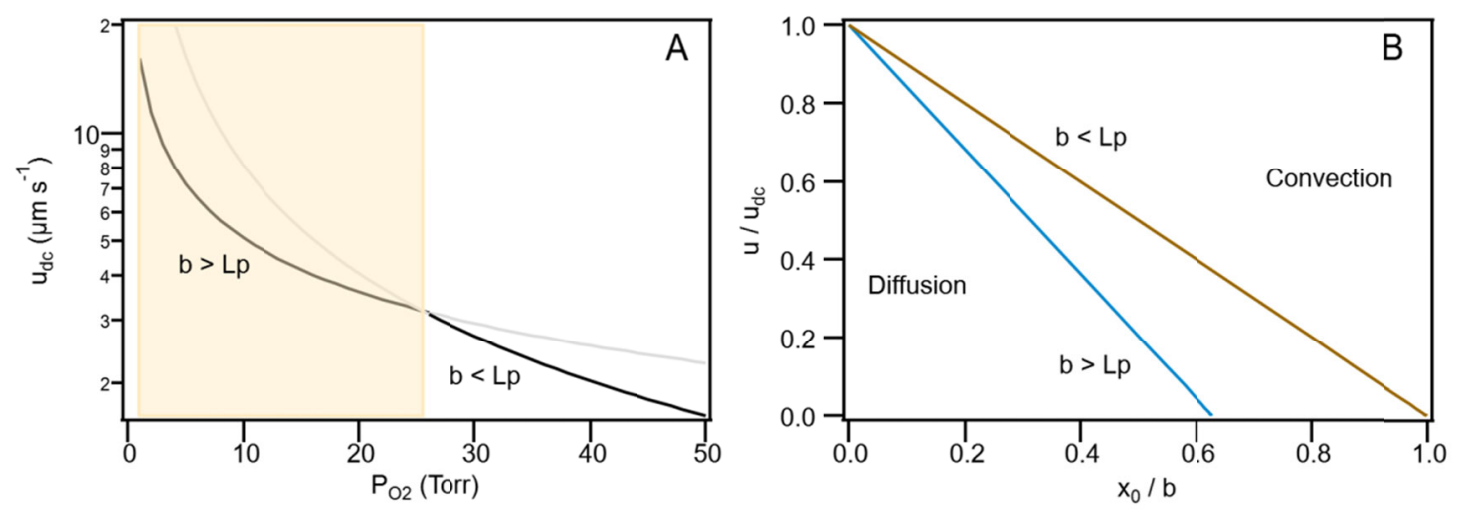

Figure 4. For $b<L_{\mathrm{p}}$ and $b>L_{\mathrm{p}}$, (A) $\boldsymbol{u}_{\mathrm{dc}}$ as a function of the $\mathrm{O}_{2}$ tension of capillary and (B) the normalized $\boldsymbol{u}$ and $x_{0}$.
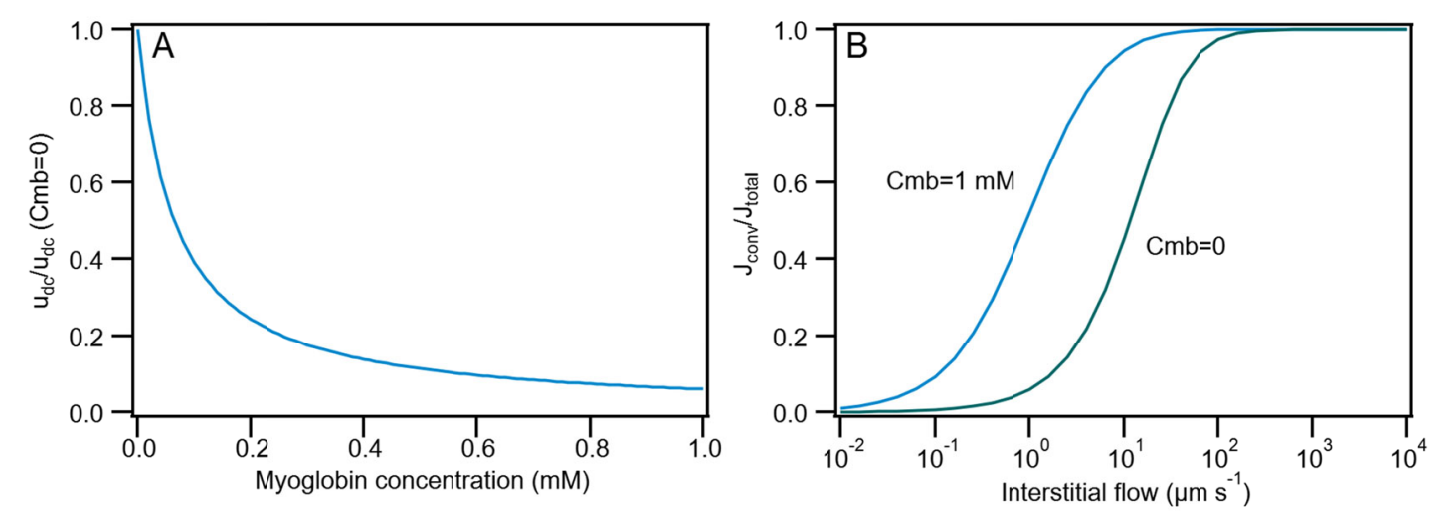
Figure 5. (A) The interstitial fluid $\boldsymbol{u}_{\mathrm{dc}}$ as a function of myoglobin concentration, $C_{\mathrm{mb}}$; (B) the ratio of $J_{\text {conv }} / J_{\text {total }}$ at $x=0$ as a function of the interstitial flow with and without myoglobin.

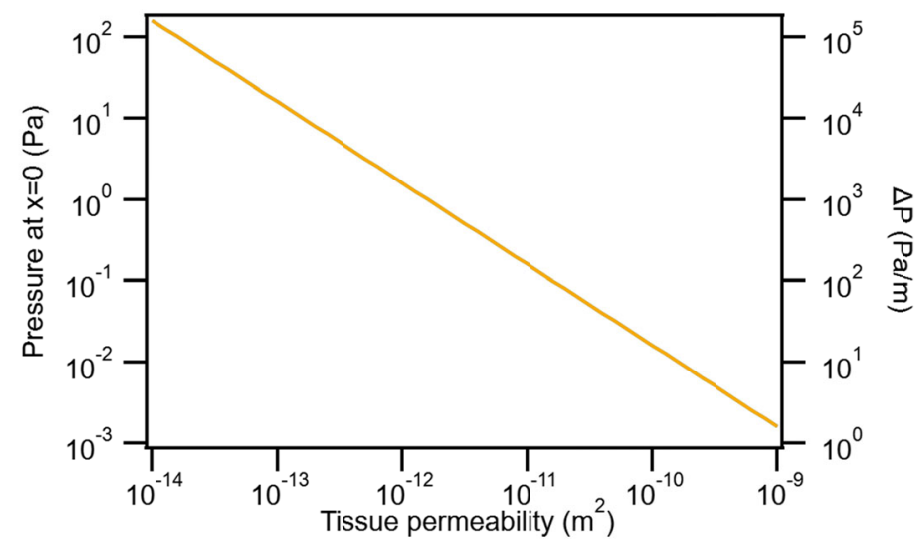

Figure 6. Pressure $(P)$ and pressure gradient $v s$. permeability at $\boldsymbol{u}=1.6 \mu \mathrm{m} / \mathrm{s}$.

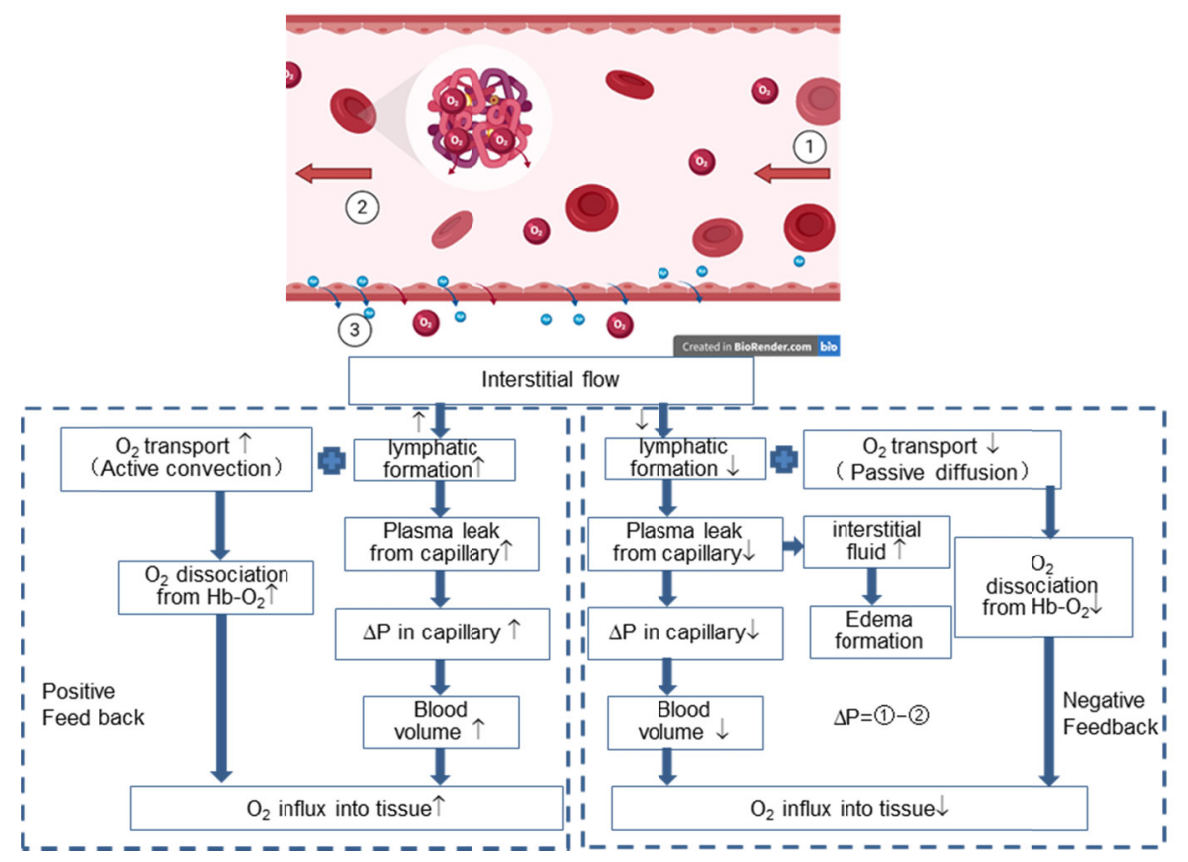

Figure 7. Influence of the interstitial flow on the $\mathrm{O}_{2}$ influx into tissue. 


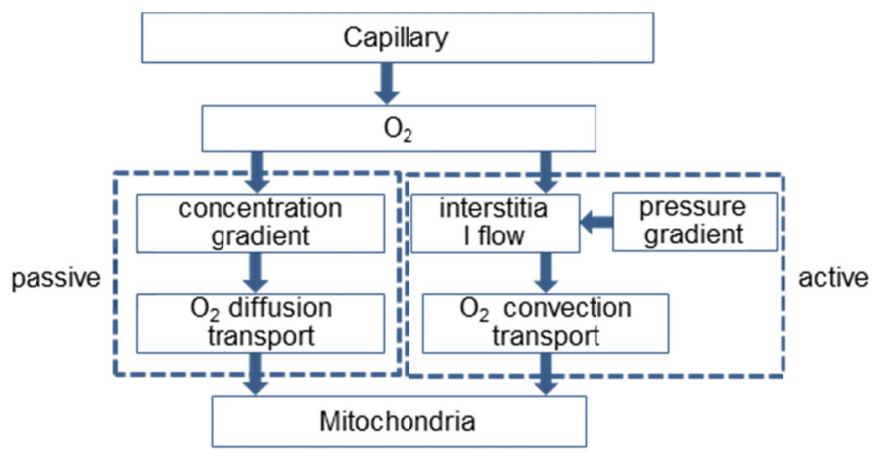

Figure 8. Summary of the active and passive $\mathrm{O}_{2}$ transport routes in tissue. 